\title{
Detection of Cryptosporidiosis in Dogs of Veterinary Clinics in Surabaya City Using Acid-Fast Staining and PCR
}

\author{
Romy Muhammad Dary Mufa ${ }^{1}$, Nunuk Dyah Retno Lastuti ${ }^{1 *}$, Djoko Legowo $^{2}$, and Mufasirin ${ }^{1}$ \\ ${ }^{I}$ Department of Veterinary Parasitology, Faculty of Veterinary Medicine, Universitas Airlangga, Surabaya-60115, Indonesia \\ ${ }^{2}$ Department of Veterinary Pathology, Faculty of Veterinary Medicine, Universitas Airlangga, Surabaya-60115, Indonesia \\ *Corresponding author's Email: nunukdyah53@gmail.com; (D) orciD: 0000-0001-9327-8893
}

\begin{abstract}
The need for maintaining pets, such as dogs, is increasing along with the human population. When individuals keep dogs as their pets, they must be aware of disease transmission from dogs. One of the disease agents transmitted from pets to their owners is Cryptosporidium spp. causing cryptosporidiosis. The aim of the present study was to detect Cryptosporidium spp. infection in dogs through a fecal examination using the acid-fast staining method (Ziehl Neelsen) confirmed with the molecular examination of Polymerase Chain Reaction (PCR). Detection of Cryptosporidium sp. in feces of dogs was set up by using an acid-fast staining method. Positive results of the acidfast staining were further confirmed using PCR. Polymerase Chain Reaction used primary AB210854 specific to the Cryptosporidium canis and S139-S141 genes which were specific primary for the Cryptosporidium parvum gene. Results of the acid-fast staining showed that $80 \%$ of the samples (40 samples from total samples) were infected with Cryptosporidium spp. Further detection using PCR showed that four samples were positive for Cryptosporidium canis infection, and two samples showed positive results of Cryptosporidium parvum infection. Dog samples were mostly infected with Cryptosporidium spp. including Cryptosporidium canis and Cryptosporidium parvum through a fecal examination using acid-fast staining and PCR.
\end{abstract}

Keywords: Acid-fast staining, Cryptosporidium spp., Dogs, PCR

\section{INTRODUCTION}

These days, demand for keeping pet dogs is increasing among people all around the world, especially due to its benefits for good mental health. On the other hand, there is an excessive need to be aware of transmitted diseases from dogs to their owners. This condition could disrupt the life quality of the animals' owners. Waterborne diseases from pets include $4.1 \%$ of total cases of human death, and around 1.8 million people are suffering from such diseases every year. Waterborne diseases are caused by infectious agents in the form of bacteria, worms, and protozoa. One of the protozoa transmitted through waterborne diseases is Cryptosporidium spp. with a size of 2-6 $\mu \mathrm{m}$. Cryptosporidium spp. generally causes digestive tract disorders called cryptosporidiosis. Cryptosporidiosis can be transmitted from animals to humans or vice versa (Medema et al., 2006) and it has been reported as a cause of diarrhea in animals, especially dogs (Fayer et al., 2001) and humans.

Cryptosporidiosis can be an acute disease, but it can turn into a chronic one, especially in immunosuppressive patients. There is no specific treatment but using supportive therapy (Gerace et al., 2019). In this regard, disease prevention is preferred by improving sanitation and hygiene. Most information about cryptosporidiosis comes from the results of histological examination of small intestinal biopsies originating from immune-deficient hosts (Gerace et al., 2019). The developmental phase can be detected in the pharynx, esophagus, stomach, duodenum, jejunum, ileum, appendix, colon, and rectum. On post mortem examination, the jejunum would be in the worst condition (Hayes et al., 1989).

The current study aimed to detect cryptosporidiosis in dogs in several animal hospitals and veterinary clinics using acid-fast staining methods (Ziehl Neelsen) and PCR method. It was expected that the results of current study can provide data on Cryptosporidium spp. in dogs that can be used later to control parasitic diseases, especially those caused by Cryptosporidium spp. 


\section{Ethical approval}

All experimental protocols and procedures were approved by the Institutional Animal Care of Indonesia. Data sampling was taken in several animal hospitals and veterinary clinics in five areas of Surabaya (north, east, south, west, and central of Surabaya). Samples observations were examined at the Laboratory of Veterinary Medicine Faculty Universitas Airlangga.

\section{Equipment and materials}

Research equipment used in the research were glass stirrer, test-tube, test-tube rack, bunsen, centrifuge, binocular microscope, sample pot, glass object and glass cover, micropipette, thermocycler, complete electrophoresis apparatus, scales, transilluminator, vortex, and water bath.

In the present study, fresh feces samples were collected from dogs that had diarrhea in several animal hospitals and veterinary clinics in Surabaya city. Other materials used were sample pots and potassium dichromate solution as preservatives for dog feces samples. The materials for acid-resistant staining were iodine Lugol solution 2\%, absolute methanol, ethanol 50\%, carbol-fuchsin, methylene blue, and sulfuric acid 1\%. Materials for DNA isolation in PCR tests were the NucleoSpin Tissue Kit (Macherey-Nagel, Germany) which includes a buffer lysis solution, absolute ethanol, proteinase K solution, Wash Buffer (WB), and Elution Buffer (BE), Gene aid DNA extraction kit, 2 x PCR Master Mix Solution (i-TaqTM) (Intron Biotechnology), DNA template, distilled water, primary oligonucleotide S139-S141 with forward 5' AAGCTCGTAGGTGGATTTCTG 3' and reverse 5' TAAGGTGCTGAAGT AAGG 3' (Hadfield et al., 2011), primary oligonucleotide AB210854 with forward 5 'TCGCGAATGGCTCATTATAACA 3 ' and reverse 5 AGGCCAATACCCTACCGTCT 3' (Samie et al., 2006). Materials for electrophoresis gel included agarose, DNA markers, ethidium bromide, electrophoresis buffer, gloves, yellow tip, blue tip, white tip, and Eppendorf tube.

\section{Procedures}

In the present study, $10 \%$ of the average cases of diarrhea in dogs at animal hospitals and veterinary clinics were sampled in a certain period of time (1 month) by taking fresh fecal samples by a swab on the dog's anus or by taking it in the cage (maximum 5 minutes after the dog defecated). The sample was inserted into the sample pot that has been filled with potassium dichromate solution as a protozoa preservative.

The acid-fast staining method was carried out after fecal solution was placed on the glass object, flattening to form a thin layer and drying it at room temperature. Then, it was fixed with absolute methanol for 1 minute. Carbolic acid solution $0.3 \%$ was dropped on the fecal smear to cover the entire surface for preparation. In the next step, it was heated with Bunsen fire until it came out steam for 3-5 minutes. It was rinsed with slowly flowing water until the dye is wasted and the alcoholic acid dripped (HCL alcohol 3\%) until the fuchsine red color disappeared. Next, it was rinsed with running water, and methylene blue solution $0.3 \%$ was dripped on the preparation until it covered the entire surface. Then, it was rinsed with running water, and dried in the open air (Rekha et al., 2016). Observations were made with a microscope with 1000x magnification. The results would be considered positive if there was an appearance of red cryptosporidium sp. oocyst with a size of 2-6 $\mu \mathrm{m}$.

Further examination was carried out using Polymerase Chain Reaction (PCR). DNA extraction was examined according to the Gene aid DNA extraction kit procedure (Azizah et al., 2014). After the DNA isolate was obtained, then replication was done using the PCR method. The cocktail composition was according to the PCR Master Mix Solution (i-TaqTM) guide. The PCR replication cycle program was adjusted to the primary used which was 30 seconds denaturation at $94^{\circ} \mathrm{C}, 30$ seconds annealing at $55^{\circ} \mathrm{C}$, and 40 seconds extension at $72^{\circ} \mathrm{C}$. The polymerase chain reaction (PCR) process used 39 cycles of reaction for the primary S139-S141, while the replication process for primary $\mathrm{AB} 210854$ used a reaction of 50 cycles consisting of 45 seconds of denaturation at $94^{\circ} \mathrm{C}, 45$ seconds of annealing at $60^{\circ} \mathrm{C}$ and 60 seconds of extension at $72^{\circ} \mathrm{C}$. Agarose gel $2 \%$ and electrophoresis at 120 volts and 2 amperes for 50 minutes were used for visualization of PCR products. Positive results of the electrophoresis were marked by the presence of the $18 \mathrm{~S}$ gene band with a length of 435 bp for primary S139-S141 and 100 bp for primary AB210854.

\section{Data analysis}

The obtained results were presented descriptively. Samples with positive results of Cryptosporidium spp. (if red Cryptosporidium spp. oocysts with 2-6 $\mu \mathrm{m}$ in size) were found on the visualization PCR products. Moreover, there was electrophoresis of the $18 \mathrm{~S}$ gene band with a length of $435 \mathrm{bp}$ for primary S139-S141 and 100 bp for primary AB210854. 
The percentage of occurrence for cryptosporidiosis which has been taken in five areas of the Surabaya city with an examination using the acid-resistant staining method can be seen in Table 1 below.

Results of examination with acid-fast staining method were $80 \%$ positive; 40 dogs indicated positive results with Cryptosporidium spp. Infection, and 20\% (10 dogs) showed negative results. Based on the regional division, samples from North Surabaya were positively infected with Cryptosporidium spp. (4 dogs, 8\%), East Surabaya (12 dogs, 24\%), South Surabaya (9 dogs, 18\%), West Surabaya (7 dogs, 14\%) and Central Surabaya (8 dogs, 16\%). According to the data, most regions have been positively infected with cryptosporidiosis. The results of the microscopic observation test on dogs' fecal samples using the acid-fast staining method can be seen in Figure 1.

The morphology of Cryptosporidium spp. oocysts was oval-shaped, and they contained Sporozoa inside them. The size of Cryptosporidium spp. was 2-6 $\mu \mathrm{m}$. The oocyst of Cryptosporidium spp. absorbed red substances (carbol-fuchsin) in the acid-fast staining method.

Positive sample results from the examination of the acid-resistant staining were followed by PCR to confirm the diagnosis species level. Results of PCR with primary AB210854 can be seen in Figure 2. Three fecal samples showed positive results of infection with Cryptosporidium parvum.

Based on the results, there were 4 sample bands with a molecular weight of $100 \mathrm{bp}$. The tape was indicated that four fecal samples were positive for infection with Cryptosporidium canis. The visualization results of PCR products with primary S139-S141can be seen in Figure 3.

Based on the results, there were two bands of samples with a molecular weight of $435 \mathrm{bp}$. This tape showed that two samples of feces were positive for infection with Cryptosporidium parvum.

Table 1. Occurrence of cryptosporidiosis in five areas of Surabaya city using an acid-fast staining method

\begin{tabular}{lccc}
\hline \multirow{2}{*}{ Areas } & \multicolumn{2}{c}{ The number of dogs } & Positive percentage Cryptosporidium spp. (\%) \\
\cline { 2 - 4 } North Surabaya & Negative & Positive & 8 \\
East Surabaya & 0 & 4 & 24 \\
South Surabaya & 1 & 12 & 18 \\
West Surabaya & 0 & 9 & 14 \\
Central Surabaya & 7 & 7 & 16 \\
Total Amount & 2 & 8 & 80 \\
\hline
\end{tabular}

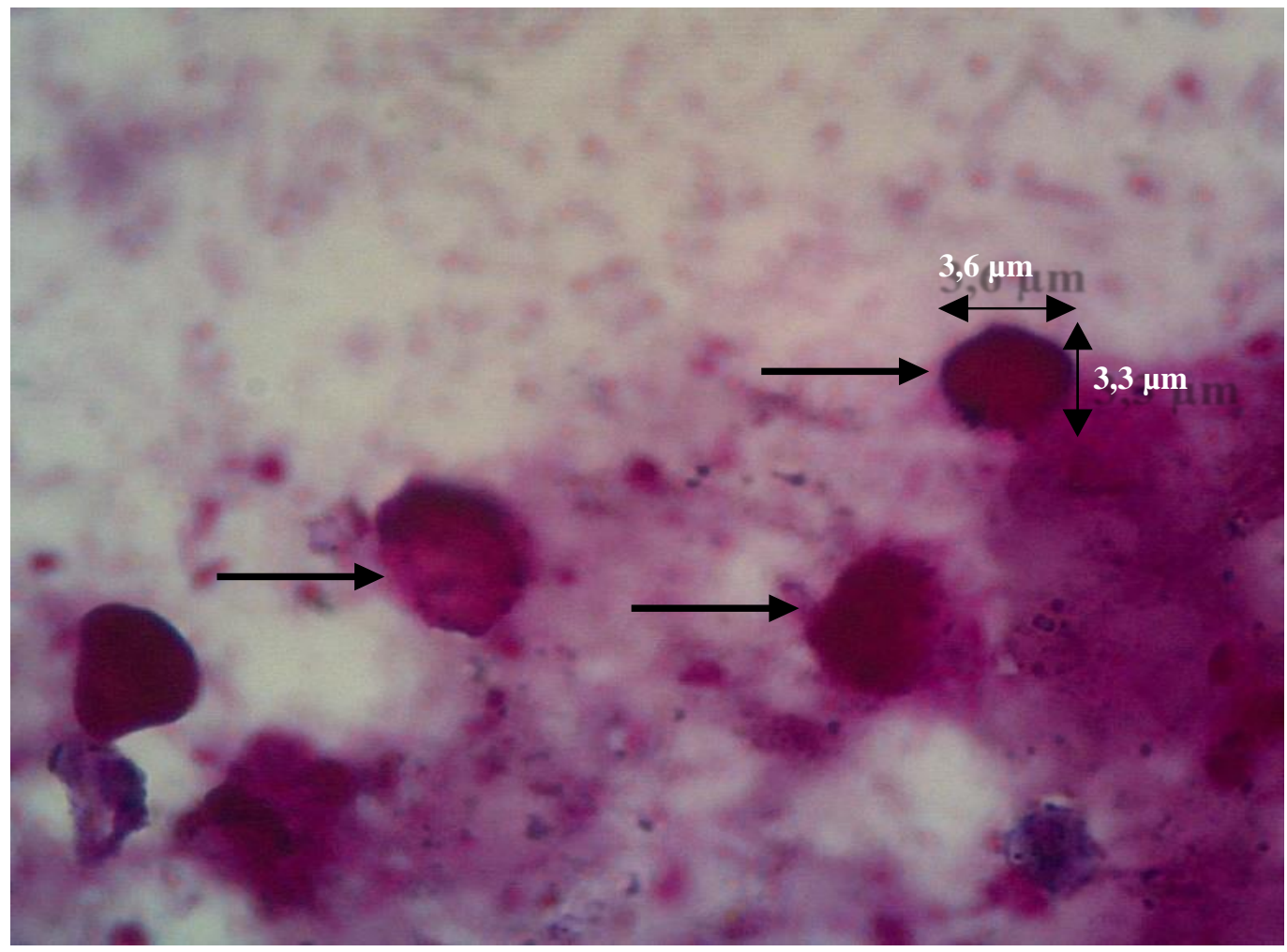

Figure 1. Cryptosporidium spp. oocyst in dogs' feces (1000× magnification) 


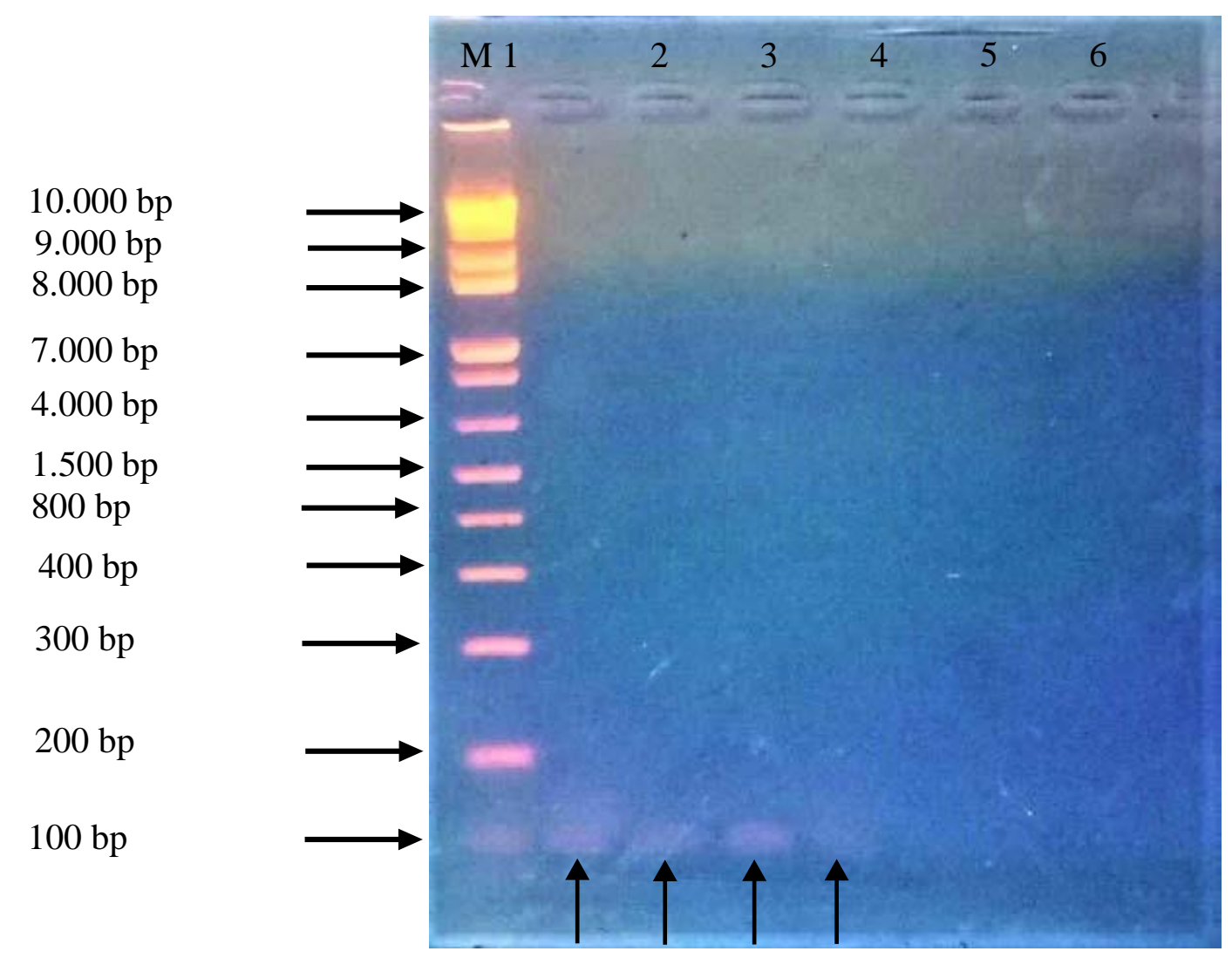

Figure 2. PCR and electrophoresis results using primary AB210854 specific to Cryptosporidium canis. M: DNA marker 1 $\mathrm{kb}, 1-7$ : DNA sample

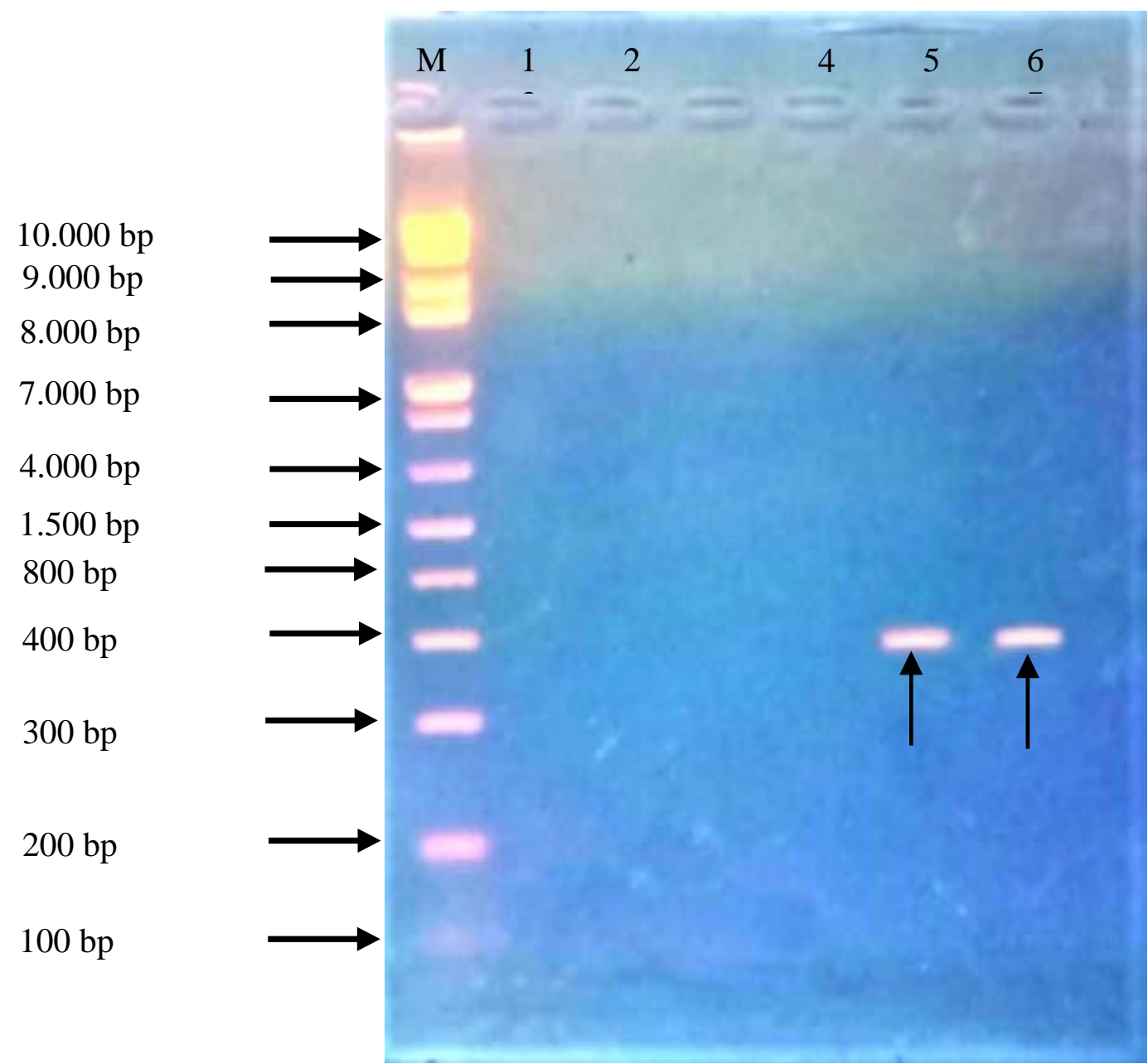

Figure 3. Results electrophoresis using the primary S139-S141 specific to Cryptosporidium parvum. M: DNA marker 1 kb, 1-7: DNA sample 
The obtained results of the present study detected Cryptosporidium spp. at $80 \%$ of all samples using the conventional method of acid-fast staining. Of 50 samples, 40 were found positive for cryptosporidiosis. Transmission of cryptosporidiosis through food and beverages contaminated by Cryptosporidium spp. was infectious through waterborne diseases. Dogs usually consume non-hygienic food and drink from outside (contaminated) or have dirty environmental habits. Giving food and especially unhygienic drinks by the owners can also cause cryptosporidiosis in dogs. A waterborne disease is a disease transmitted through water contaminated by infectious agents from the host or carriers. When water containing an infectious agent is consumed, the disease could occur to another host (Kusnoputranto and Susanna, 2000). A large number of detected samples could be caused by fecal sampling taken in February 2017 during a rainy season. Gastrointestinal protozoan infections often occur in rainy seasons or around October to April (Mekibib and Sheferaw, 2018; Sursal et al., 2020). A rainy season is the optimum environmental condition for infectious agents that are waterborne diseases. Sanitation factors, cage cleanliness, and place of keeping dogs are important factors for prevention of protozoan infections (Tangtrongsup et al., 2020).

The current study found a variety of Cryptosporidium spp. confirming the modern methods, namely the PCR technique. There were two variations, namely Cryptosporidium canis and Cryptosporidium parvum. The Cryptosporidium canis species are species of Cryptosporidium which attacks dogs, and Cryptosporidium parvum commonly attacks humans who have contact with animals or live in tropical regions (Current et al., 1983). Cryptosporidium canis was identified as a dog genotype (Fayer et al., 2000). Natural Cryptosporidium canis infections have been reported for wolves (Vulpes vulpes), coyotes (Canis latrans), and more than 30 humans (Zhou et al., 2004).

The diagnosis of cryptosporidiosis was done by examining samples using a fecal examination of the host with acidfast staining method (Ziehl Neelsen) and molecular examination using PCR. The diagnosis of laboratory cryptosporidiosis was done by finding causative agents, among others, and also by parasitological and molecular methods (Osman et al., 2015). Cryptosporidium spp. is round and oval in shape. The size of Cryptosporidium spp. is 2-6 $\mu \mathrm{m}$, and it is difficult to detect using the regular, sedimentary, and buoyant fecal examination method. However, it was conveniently detected by an acid-fast staining method. This is due to Cryptosporidium spp. is an acid-resistant protozoan, so it could absorb carbol-fuchsin (acid) dyes in an acid-fast staining method. In addition to the acid-fast staining method, cryptosporidiosis was diagnosed by molecular methods, such as PCR to confirm the positive samples of acid-resistant staining method.

The principle of PCR method was to multiply nucleic acids through a process of denaturation, annealing, and extension using a thermocycler machine. This method has high sensitivity, compared to the conventional fecal examination methods. Polymerase Chain Reaction has various advantages that make it practical especially in the molecular biology field (Broll, 2010). Using molecular methods, such as PCR, was carried out to detect Cryptosporidium to species level. DNA amplification of Cryptosporidium spp. aimed at 18S rRNA gene. Primary positive results of S139S141 for specific Cryptosporidium parvum showed a band of 435 bp (Nichols et al., 2003), while primary positive results AB210854 for specific Cryptosporidium canis showed a band 100 bp in electrophoresis (Brody et al., 2004).

\section{CONCLUSION}

The present study concluded that detection of Cryptosporidium spp. with the acid-resistant staining method (Ziehl Neelsen) and PCR in dog feces samples showed positive results. Cryptosporidium species that infect dogs in the current study include Cryptosporidium canis and Cryptosporidium parvum. It suggested that this method can be useful for detection of Cryptosporidium species in different animals specially in pets.

\section{DECLARATIONS}

\section{Authors' contribution}

All authors contributed equally to this study.

\section{Competing interests}

Authors declare no competing interest.

\section{Ethical considerations}

Ethical issues (including plagiarism, consent to publish, misconduct, data fabrication and/or falsification, double publication and/or submission, and redundancy) have been checked by the authors. 


\section{REFERENCES}

Azizah NN, Mazieda MN, Listyorini D, and Biologi DJ (2014). Optimization DNA isolation and purification petunia hybrida picotee rose series with isolation kit geneaid. Proceeding Biology Education Conference, 11(1) 273-278. Available at: https://jurnal.uns.ac.id/prosbi/article/view/7726/6892

Brody JR, Kadkol SS, Hauer MC, Rajaii F, Lee J, and Pasternack GR (2004). pp32 reduction induces differentiation of TSU-Pr1 cells. The American Journal of Pathology, 164(1): 273-83. DOI: https://www.doi.org/10.1016/S0002-9440(10)63117-3

Broll H (2010). Quantitative real-time PCR, molecular biological and immunological techniques and applications for food chemists. John Wiley and Sons, Inc Hoboken, New Jersey, 16: 59-83. Available at: https://download.ebookshelf.de/download/0000/5744/83/L-G-0000574483-0002308263.pdf

Current WL, Reese NC, Ernst JV, Bailey WS, Heyman MB, and Weinstein WM (1983). Human cryptosporidiosis in immunocompetent and immunodeficient persons. Studies of an outbreak and experimental transmission. New England Journal of Medicine, 308(21): 1252-1257. DOI: https://www.doi.org/10.1056/NEJM198305263082102

Fayer R, Trout JM, Xiao L, Morgan UM, Lal AA, and Dubey JP (2001). Cryptosporidium canis n. spp. from domestic dogs. The Journal of Parasitology, 87(6): 1415-1422. DOI: https://www.doi.org/10.2307/3285311

Fayer R, Morgan U, and Upton SJ (2000). Epidemiology of Cryptosporidium: transmission, detection and identification. International Journal for Parasitology, 30: 1305-1322. DOI: https://www.doi.org/10.1016/s0020-7519(00)00135-1

Gerace E, Presti VDML, and Biondo C (2019). Cryptosporidium infection: Epidemiology, pathogenesis, and differential diagnosis. European Journal of Microbiology and Immunology, 9(4): 119-123. DOI: https://www.doi.org/10.1556/1886.2019.00019

Hadfield SJ, Robinson G, Elwin K, and Chalmers RM (2011). Detection and differentiation of Cryptosporidium spp. in human clinical samples by use of real-time PCR. Journal of Clinical Microbiology, 49(3): 918-924. DOI: https://www.doi.org/10.1128/JCM.01733-10

Hayes EM, Matte TD, OBrien TR, McKinley TW, Logsdon GS, Rose JB, Ungar BLP, Word DM, Wilson MA, Long EG et al. (1989). Large community outbreak of cryptosporidiosis due to contamination of a filtered public water supply. The New England Journal of Medicine, 320(21): 1372-1376. DOI: https://www.doi.org/10.1056/NEJM198905253202103

Kusnoputranto H, and Susanna D (2000). Kesehatan lingkungan. Universitas Indonesia. Available at: https://r2kn.litbang.kemkes.go.id/handle/123456789/76470

Mekibib B, and Sheferaw D (2018). Enteric protozoa of dogs: prevalence, associated risk factors and owners' awareness in and around Hawassa town, Ethiopia. Ethiopian Veterinary Journal, 22(1):59-73. Doi: https://doi.org/10.4314/evj.v22i1.5

Medema G, Teunis P, Blokker M, Deere D, Davison A, Charles P, and Loret JF (2006). WHO guidelines for drinking water quality: Cryptosporidium. WHO, New $\quad$ York, p. $138 . \quad$ Available at: http://apps.who.int/iris/bitstream/handle/10665/44584/9789241548151_eng.pdf;jsessionid=B6838F2FC79989BD4D771D9535D $126 \mathrm{C} 9$ ? sequence $=1$

Nichols RAB, Campbell BM, and Smith HV (2003). Identification of Cryptosporidium spp. oocysts in United Kingdom noncarbonated natural mineral waters and drinking waters by using a modified nested PCR-restriction fragment length polymorphism assay. Applied and Environmental Microbiology, 69(7): 4183-4189. DOI: https://www.doi.org/10.1128/aem.69.7.4183-4189.2003

Osman M, Bories J, El Safadi D, Poirel MT, Gantois N, Benamrouz-Vanneste S, and Viscogliosi E (2015). Prevalence and genetic diversity of the intestinal parasites Blastocystis sp. and Cryptosporidium spp. in household dogs in France and evaluation of zoonotic transmission risk. Veterinary Parasitology, 214(1-2): 167-170. Doi: https://doi.org/10.1016/j.vetpar.2015.09.015

Rekha KM, Puttalakshmamma GC, and D'Souza PE (2016). Comparison of different diagnostic techniques for the detection of cryptosporidiosis in bovines. Veterinary world, 9(2): 211-215. DOI: https://doi.org/10.14202/vetworld.2016.211-215

Samie A, Bessong PO, Obi CL, Sevilleja JEAD, Stroup S, Houpt E, and Guerrant RL (2006). Cryptosporidium species: preliminary descriptions of the prevalence and genotype distribution among school children and hospital patients in the Venda region, Limpopo Province, South Africa. Experimental Parasitology, 114(4): 314-322. DOI: https://www.doi.org/10.1016/j.exppara.2006.04.007

Sursal N, Simsek E, and Yildiz K (2020). Occurrence and First Molecular Characterization of Cryptosporidium felis in a Cat in Turkey. Kafkas Üniversitesi Veteriner Fakültesi Dergisi, 26(6): 833-837. Link: https://vetdergikafkas.org/uploads/pdf/pdf_KVFD_2742.pdf

Tangtrongsup S, Scorza AV, Reif JS, Ballweber LR, Lappin MR, and Salman MD (2020). Seasonal distributions and other risk factors for Giardia duodenalis and Cryptosporidium spp. infections in dogs and cats in Chiang Mai, Thailand. Preventive Veterinary Medicine, 174, 104820. Doi: https://doi.org/10.1016/j.prevetmed.2019.104820

Zhou L, Fayer R, Trout JM, Ryan UM, Schaefer FW, and Lihua Xiao L (2004). Genotypes of Cryptosporidium species infecting furbearing mammals differ from those of species infecting humans. Applied and Environmental Microbiology, 70(12): $7574-7577$. DOI: https://www.doi.org/10.1128/AEM.70.12.7574-7577.2004 